\title{
Cartas do CIRANDAR: movimento co-partilhado de formação acadêmico-profissional docente
}

\author{
Letters from CIRANDAR: co-shared movement of \\ academic and professional training for teachers
}

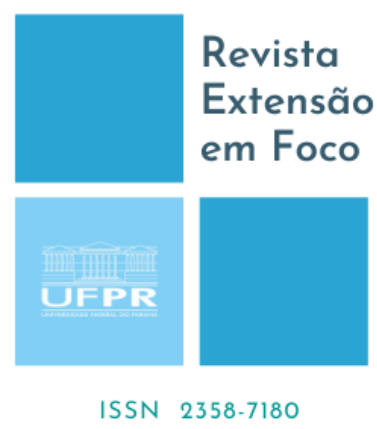

Elena Maria Billig Mello'

\begin{abstract}
RESUMO
Esta escrita é composta por um conjunto de cartas escritas a partir do projeto de extensão CIRANDAR 2020: rodas de investigação na escola, coordenado por um coletivo docente da Universidade Federal de Rio Grande - FURG, no qual participei. Estas cartas relatam um pouco da minha experiência docente, escritas a partir das cartas recebidas da coordenação do CIRANDAR, sendo que a primeira foi a resposta especialmente à indagação: "Como cheguei até aqui?"; na segunda introduzo a escolha da temática que desejava estudar; a terceira carta aprofundei a temática e a quarta carta compôs o meu registro sobre a minha leitura entre pares. Considero que foi um movimento de revisitar, enquanto docente, minha formação acadêmico-profissional de forma co-partilhada e coletiva.
\end{abstract}

Palavras-chave: Formação acadêmico-profissional. Experiência docente. Inovação pedagógica.

\begin{abstract}
This writing is composed of a set of letters written from the outreach project CIRANDAR 2020: research circles at the school, coordinated by a teaching collective from the Federal University of Rio Grande FURG, in which I participated. These letters relate a little of my teaching experience, written from the letters received from the coordination of CIRANDAR, the first being the answer especially to the question: "How did I get here?"; in the second I introduce the choice of the theme that I wanted to study; the third letter deepened the theme and the fourth letter composed my record about my reading among peers. I consider that it was a movement to revisit, as a professor, my academic-professional training in a co-shared and collective way.
\end{abstract}

Keywords: Academic-professional training. Teaching experience. Pedagogical innovation.

\section{PALAVRAS INICIAIS}

A presente escrita se constitui por um conjunto de cartas escritas a partir do projeto de extensão CIRANDAR 2020: rodas de investigação na escola, coordenado por um coletivo docente da Universidade Federal de Rio Grande - FURG, no qual participei.

Este conjunto é formado de quatro cartas, que foram escritas a partir das cartas recebidas da coordenação do CIRANDAR, sendo que a primeira carta foi a resposta à

\footnotetext{
${ }^{1}$ Doutora em Educação. Universidade Federal do Pampa (UNIPAMPA). Uruguaiana. Rio Grande do Sul. Brasil. E-mail: profelena@gmail.com Orcid: https://orcid.org/0000-0003-0366-3021
} 
indagação: "Como cheguei até aqui?"; na segunda fiz a escolha da temática inovação pedagógica na formação acadêmico-profissional, que desejava estudar; na terceira carta aprofundei a temática e a quarta carta compôs a minha leitura entre pares.

Considero que o CIRANDAR, evento que acontece desde 2012, coordenado pela Universidade Federal de Rio Grande - FURG, interpelou-me com este espaço-tempo de escrita, desde a edição 2018. Nesta última edição, em 2020, em que as rodas se desenrolaram no formato on-line, possibilitou um movimento bem especial em função do isolamento e do ensino remoto decorrente da pandemia da Covid-19.

E ancorada em Larrosa $(2018$, p. 8), pergunto-me “[...] mas o que era isso, o que estive fazendo durante toda a minha vida?' [...] sobre o que é isso de ser professor chega a ser uma pergunta tardia, de velho, a que só pude responder concretamente, a partir de minhas próprias maneiras de sê-lo [...]".

\section{CARTA 1: "Como cheguei até aqui?"}

Para a escrita da minha primeira carta, foi nos instigado a escrever inspirada no questionamento: “Como cheguei até aqui?" E também com o propósito de contar um pouco de quem sou eu e do meu percurso-experiência enquanto pessoa-profissional da área de educação.

Escrever sobre a minha formação e atuação acadêmico-profissional foi um movimento desafiador e, ao mesmo tempo, prazeroso ao envolver saberes, conhecimentos, memórias em relação aos que comigo partilharam momentos em diversos tempos-espaços.

A significação de experiência que aqui trago está inspirada em Larrosa (2018, p. 18), que diz:

\footnotetext{
Não se escreve sobre a experiência, mas sim a partir dela. O mundo não é somente algo sobre o que falamos, mas algo a partir de que falamos. É a partir daí, a partir do nosso ser-no-mundo, que temos algo para aprender, algo para dizer, algo para contar, algo para escrever. Além disso, as palavras não apenas representam o mundo, mas também o abrem, não são apenas uma ferramenta, mas também um caminho ou uma força.
} 
Sou servidora docente pública desde 1986, primeiramente da rede estadual do RS e após da rede federal, envolvida sempre em atividades acadêmicas, com foco na política educacional e na formação docente.

Recordo que a minha formação em nível médio na Habilitação Magistério, no final de 1970 e início dos anos 80, esteve impregnada do viés tecnológico e gerencialista. No final dos anos 80, realizei graduação numa universidade comunitária; e, anos mais tarde, já como docente nessa universidade, cursei o mestrado e o doutorado em educação em universidades públicas: UFSM (concluí no final de 2002) e UFRGS (finalizei em maio de 2010), respectivamente.

Na graduação conheci a obra de Paulo Freire, acontecimento que passou a interpelar minha vida pessoal e profissional até hoje, impregnada na amorosidade, na ética, na estética, no diálogo, no Ser-Mais ontológico, na humanização, na criticidade, entre outros princípios presentes no processo de esperançar na/pela educação. Esse olhar freiriano esteve presente na minha docência como formadora de professores/as em cursos de Magistério em nível médio e da Educação Superior, quando iniciei minha carreira profissional na educação em 1986. Acredito eu que ainda continua premente no meu modo de ser docente na universidade.

Neste meu percurso formativo, o mestrado e o doutorado em Educação constituíram-se em espaços-tempos potentes para a minha fundamentação teóricoepistemológica na linha de política educacional e formação docente, especialmente (com)vividos com a profa. Maria Beatriz Luce.

Atualmente estou professora associada na Universidade Federal do Pampa, em Uruguaiana-RS, atuando em atividades de gestão, extensão, pesquisa e ensino em cursos de licenciatura e na pós-graduação - cursos de mestrado e doutorado em educação e em ensino, dos campi Uruguaiana e Bagé.

Nesse espaço-tempo tive o privilégio de conhecer colegas que se tornaram amigos/as nesse caminhar coletivo, quando nos envolvemos e nos instigamos a refletir, criar, planejar, socializar, compartilhar. Com a docência co-partilhada cresci como pessoa e profissional.

Destaco o CIRANDAR que conheci nos últimos anos, pois conheci outra forma de me colocar e envolver pelas rodas de conversa. Fui cativada! 
Em 2020 deparo-me com esse momento incomum e insólido provocado pela pandemia da Covid-19, que tem escancarado cruelmente as exclusões, as divisões sociais, culturais, econômicas, políticas, educacionais, quando preconceitos, injustiças, indiferenças, discriminações vêm à tona ... Há um desgoverno e uma a-política (ausência de política) em áreas sociais cruciais, como a saúde e a educação.

Como um suspiro... o CIRANDAR acontece novamente... E aqui estou eu, de novo, junto a um grupo de colegas que iniciamos a nos conhecer...

Seja bem-vindo CIRANDAR, como a florida primavera, que nos faz re-existir e resistir! Este momento que importa...

Figura 1 - Foto flores da orquídea

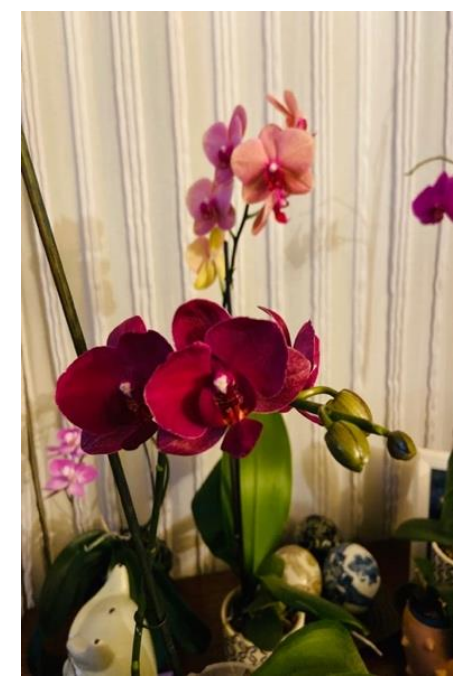

Fonte: Autoria própria.

Uruguaiana, primavera 2020.

Abraços da Elena.

\section{CARTA 2: Escolha da temática inovação pedagógica}

Esta semana passei pelo senhor que vende rosas... (quem mora em Uruguaiana sabe de quem falo) ... e senti vontade de enfeitar a minha casa com um lindo buquê. Como sei o quanto esse senhor entende de rosas, perguntei qual daquelas lindas e coloridas rosas durariam mais. Ele mostrou os botões das rosas laranjas, fiquei receosa no primeiro 
momento, mas a cor linda e diferente me entusiasmou. Trouxe-as para casa e a alguns dias elas vêm, em silêncio, lentamente, abrindo e a perfumar lindamente a sala.

\section{Figura 2 - Foto vaso de rosas}

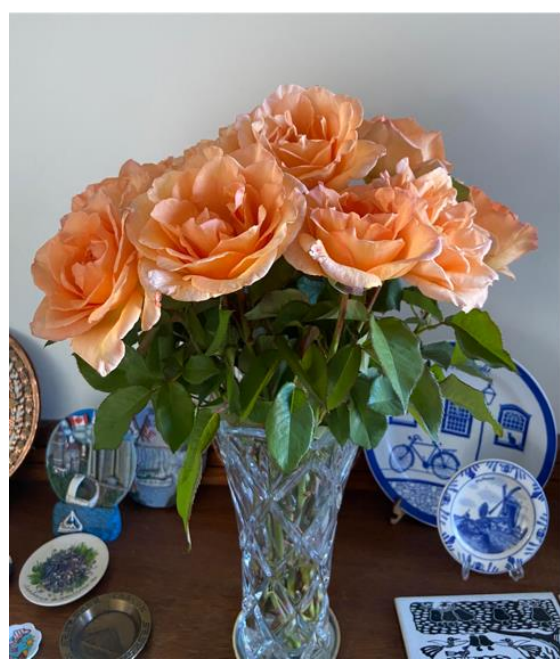

Fonte: Autoria própria.

Assim como essas rosas deste meu vaso (Figura 2), eu venho desabrochando... Tenho percebido que estou me constituindo como docente a cada encontro virtual que tenho tido neste momento de trabalho remoto, com mais diversos grupos, com colegas mais próximos e mais diferentes... As demandas aumentaram muito... quantos novos grupos de trabalho pelo WhatsApp! Isso me faz criar mais resistência e me fortalecer, como as rosas.

Sabem que, como docente e pesquisadora, continuo envolvida em temáticas relacionadas às políticas educacionais na formação acadêmico-profissional, e, nos últimos anos, estou sendo interpelada pelas ideias de inovação na educação e quanto tudo isso me envolve ético-esteticamente.

Inovação nos mobiliza, nos inquieta, nos deixa curiosos, nos incita a usar outras formas de saber-fazer, a olhar em diferentes perspectivas... e sempre como uma ação coletiva. Minha inquietação investigativa perpassa em saber mais como compreender a inovação pedagógica além da inovação tecnológica... Especialmente neste tempo tão insólito causado pela pandemia, que nos separa, que escancara as diferenças, os preconceitos, as dificuldades, e, também, causa ansiedades e esgotamento... Uma das 
"descobertas" maravilhosas que fiz, que considero inovador neste meu constituir docente, foi esta possibilidade da escrita narrativa por meio de cartas, como essa.

Este espaço-tempo do CIRANDAR está a ensinar-me, amorosamente, a saber escutar mais e observar o quanto aprendo a inovação coletivamente, com foco nas pessoas, com ousadia e coragem, re-significando a "vida"; com poesia também...

Figura 3 - Poema Eulíricas seguir a ciência das flores

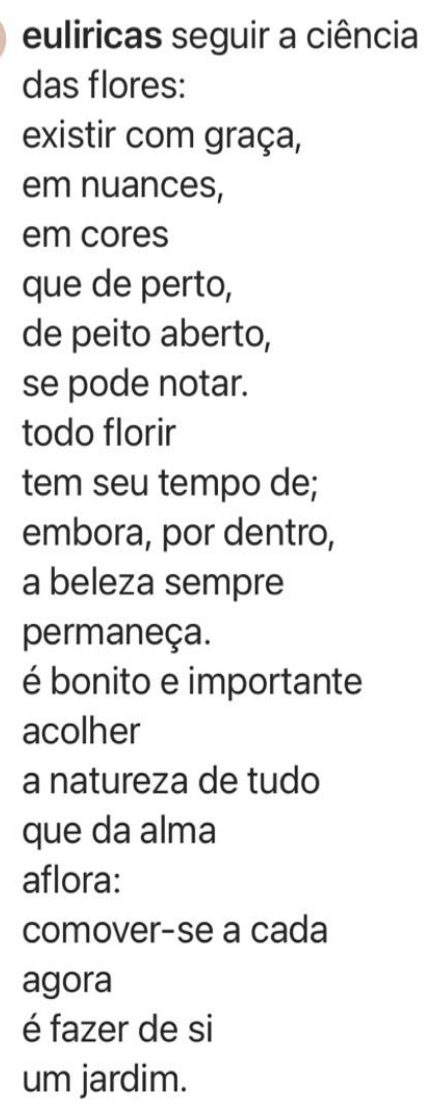

Fonte: Instagram eulíricas

Uruguaiana, 04 de novembro de 2020.

Abraços carinhosos e perfumados da Elena.

CARTA 3: Inovação pedagógica na política de formação docente: é possível? 
Aprofundar as reflexões que o CIRANDAR 2020 oportunizaram, a partir dos encontros com grupos de coordenadores/as e de professoras participantes no grupo do CIRANDARURUPEL ${ }^{2}$, é um exercício de escrita muito interessante.

Neste momento insólido, como um suspiro... o CIRANDAR aconteceu novamente... E aqui estou eu novamente participando deste espaço-tempo, que nos faz re-nascer e resistir.

Inicialmente, fui instigada a escrever inspirada no questionamento: "Como cheguei até aqui? E também com o propósito de contar um pouco de quem sou eu e do meu percurso-experiência enquanto pessoa-profissional da área de educação.

Nesse sentido, com o CIRANDAR tenho percebido minha constituição como docente de forma mais criativa e crítico-reflexiva e interpelada pelas ideias de inovação na educação.

A inovação pedagógica me mobiliza, me inquieta, me deixa curiosa, me incita a usar outras formas de saber-fazer, a olhar em diferentes perspectivas... e sempre em ações coletivas.

Minha inquietação investigativa perpassa em saber mais como compreender esta inovação pedagógica... Este espaço-tempo do CIRANDAR está a ensinar-me, amorosamente, a saber escutar mais e observar o quanto aprendo a inovação coletivamente, com foco nas pessoas, com ousadia e coragem, re-significando a "vida".

Nesse sentido, aprofundando teoricamente com autores que influenciam esta perspectiva inovadora na educação, como para Carbonell (2002, p. 82) que "a inovação é o resultado de um sábio e frágil equilíbrio entre o saber acumulado coletivamente e a necessidade permanente de repensá-lo"; Cunha (2003, p. 151) ao mencionar que inovação “é fazer uma profissão de fé, que envolve a nossa condição de humanidade e a possibilidade de transformar os silêncios em possibilidades." A inovação pedagógica possibilita um relevante movimento que interpela a todos/as no sentido da compreensão nas/das/pelas experiências, que no sentido de Larrosa (2018), nos tocam, nos inquietam, nos mobilizam, nos desafiam a outros olhares além dos cotidianos.

\footnotetext{
${ }^{2}$ CIRANDARURUPEL $=$ grupo do CIRANDAR 2020 composto por participantes de Uruguaiana e Pelotas, sob minha coordenação e da profa. Diana Paula Salomão de Freitas.
} 
Coaduno também com Leite; Genro; Braga (2011, pp. 25-26) que percebem que: “A inovação pedagógica vem para alterar uma certeza, produzir dúvidas, gerar inquietação, para ajudar a pensar diferente do modo considerado normal, para ativar outras zonas do cérebro que não aquelas do caminho neuronal preferencial."

A inovação na educação nos "tira o chão", desestabiliza, produz incertezas, receios, dúvidas, angústias, ansiedades..., como colocam as autoras já referidas, a inovação nos provoca a "[...] saber mais, pelo entender o que não se entende, por compreender pontos de vista que à primeira vista podem parecer distanciados entre si." (LEITE; GENRO; BRAGA, 2011, pp. 25-26).

Nesse sentido, entendo que a inovação pedagógica possibilita emoção, envolvimento, capacidade de ousar, de criar, de enxergar em outras dimensões, de outras formas o que parece óbvio. Esse movimento inovador na educação caracteriza-se como constitutivo, coletivo, participativo, re-construtivo, criativo, que exige coragem e ousadia e envolve amorosidade e humanização.

Expresso aqui as contribuições do meu grupo de pesquisa - o GRUPI ${ }^{3}$, que tem me possibilitado avançar na concepção e nos princípios da inovação pedagógica na formação docente, além da política educacional oficial das diretrizes curriculares nacionais para formação de professores (BNC-Formação docente), e da Base Nacional Comum Curricular (BNCC), que apresentam concepção restrita de inovação pedagógica a "metodologias e estratégias que desenvolvam, nos estudantes, a criatividade e a inovação”. (BRASIL, MEC, RESOLUÇÃO CNE/CP Nº 2/2019).

Ao pensar além desse aspecto metodológico, compreendo que a inovação na educação se constitui numa ciência pedagógica crítica e consiste em intervenções educacionais, criadas por decisões coletivas e participativas de sujeitos em formação acadêmico-profissional, com a intencionalidade de promover mudanças nas estratégias administrativo-pedagógicas de re-construção de conhecimentos e de processos educacionais que se alinhem às transformações histórico-sociais necessárias aos fins pretendidos. (MELLO; SALOMÃO DE FREITAS, 2020).

Encerro no esperançar freireano de que me mobiliza a ser mais crítica, reflexiva, humana, criativa no meu com-viver de forma mais ético-estética, e acreditando que isso

\footnotetext{
${ }^{3}$ GRUPI = Grupo de pesquisa em Inovação Pedagógica na Formação Acadêmico-Profissional de Profissionais da Educação. Universidade Federal do Pampa/UNIPAMPA.
} 
me fortalece para que a inovação pedagógica na política de formação docente ainda seja possível.

Uruguaiana, 31 de março de 2020.

Elena Maria Billig Mello

\section{CARTA 4: Registro da leitura da carta de uma colega}

Querida colega professora,

É sempre muito bom ler uma carta em que a amorosidade pela profissão docente está transbordando nas palavras. Adorei saber que está nesta caminhada docente, reinventando-se, especialmente ao conviver com o teu aluno autista... como eles nos ensinam, né?

Pelo que pude perceber tu estás no início da trajetória docente e eu no final da minha... são mais de 34 anos como docente, em que a maioria do tempo trabalhei como formadora de docentes. Quanta responsabilidade nossa profissão nos coloca! Também nos envolve por inteiro, trabalhamos com pessoas e os sentimentos aí se perpassam...

Historicamente, a nossa profissão é desvalorizada pelas políticas de governo, que desconsideram que somos essenciais para o cumprimento de um dos principais direitos sociais dos cidadãos: a educação - direito público subjetivo. E com a pandemia da COVID-19 percebemos que piorou em relação a isso. Não somos nem grupo prioritário para a vacinação!

Acredito que a coletividade teria mais força para reivindicarmos nossos direitos... mas cadê a "união" da nossa categoria profissional?! Porém, não podemos nos acuar... Assim, nos pequenos grupos que nos envolvemos, como o CIRANDAR, podemos dialogar, socializar e trocar nossas ideias, pensamentos, desejos...

Sobre isso expresso o que penso com Larossa (2002, p. 21): 


\begin{abstract}
Eu creio no poder das palavras, na força das palavras, creio que fazemos coisas com as palavras e, também, que as palavras fazem coisas conosco. As palavras determinam nosso pensamento porque não pensamos com pensamentos, mas com palavras, não pensamos a partir de uma suposta genialidade ou inteligência, mas a partir de nossas palavras. E pensar não é somente "raciocinar" ou "calcular" ou "argumentar", como nos tem sido ensinado algumas vezes, mas é sobretudo dar sentido ao que somos e ao que nos acontece. E isto, o sentido ou o sem-sentido, é algo que tem a ver com as palavras. E, portanto, também tem a ver com as palavras o modo como nos colocamos diante de nós mesmos, diante dos outros e diante do mundo em que vivemos. E o modo como agimos em relação a tudo isso.
\end{abstract}

Palavras faladas ou escritas em que manifestamos nossas ideias, pensamentos, desejos, anseios... enfim, aquilo que, de alguma maneira, nos afeta e afeta os outros. Em casa, nestes tempos insólitos, estamos aprendendo também a (com)viver conosco mesmo e com os que nos rodeiam, a olharmos com mais "cuidado" a nossa casa, a descobrir em nós outras possibilidades (como cozinhar, pintar, ler, bordar, escutar música, cuidar dos nossos "pets" e das plantas ... enfim há muitas outras brechas...), em que aprendemos a dimensão ético-estética, que se expressa a todo instante no nosso espaço-tempo. Me pergunto, com Larrosa (2002): "E o modo como agimos em relação a tudo isso."

Nas tuas palavras registradas na carta, mostra que está se reinventando, especialmente nesta experiência com o menino autista, que te toca. Queria saber mais sobre isso? Poderia descrever momentos, com reações e emoções que aí transbordam. Anotas os momentos vivenciados com ele? Tu retomas depois para planejar o próximo encontro? Como a ludicidade tem contribuído não somente para o aprendizado de palavras, mas também para a forma como ele se coloca no mundo? O que efetivamente mudou em ti com esta vivência? Como tem agido com os outros com esta experiência docente? Como tem se colocado em relação a si mesmo, aos outros e o mundo em que vivemos? Acredito que tenhas ainda muito o que relatar, de forma livre, sem se "podar", olhando-se com curiosidade. As palavras nos ajudam a dar sentido (ou não) a este momento.

Fiquei curiosa em saber mais ... Também fiquei a imaginar como tu és, que valores priorizas, ... alguns posso perceber ao escolher ser docente, em que pelas tuas próprias palavras: “... amo ser professora!”. Somos duas! Também fiz esta escolha e, cada vez mais, envolvo-me emocionalmente, com amorosidade, e sabendo que temos que aprender sempre. Nunca estamos “prontas”! Isso que nos mobiliza e dá sentido a nossas vidas! 
Envio uma foto que tirei da janela do meu quarto, para te inspirar também, pois, constantemente, aprecio esta imensidão inspiradora...

\section{Figura 4 - Foto janela}

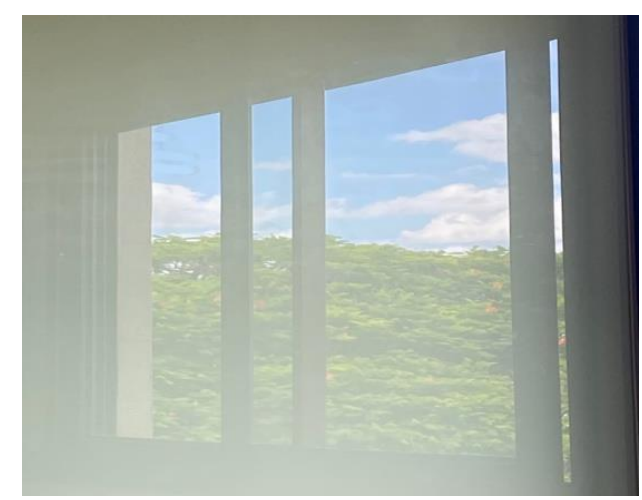

Fonte: Autoria própria.

Uruguaiana, 22 de fevereiro de 2021.

Um abraço afetuoso da Elena.

\section{REFLEXÕES FINAIS}

Considero que o CIRANDAR 2020 foi um movimento de revisitar, enquanto docente, minha formação acadêmico-profissional de forma co-partilhada e coletiva, a partir dos movimentos teórico-conceituais de inovação pedagógica e das experiências daí suscitadas.

O processo de formação docente, mediado pelas reflexões a partir das cartas escritas realizadas nas rodas de conversas, constituiu-se neste espaço-tempo próprio deste Evento. Em abril de 2021, a síntese das experiências estéticas de cada uma das Rodas foi socializada com todos/as participantes, com sensibilidade e significação, representando o coletivo da inovação pedagógica que o CIRANDAR nos proporcionou.

Termino com a passagem do livro de Larrosa intitulado "Esperando não se sabe o quê: sobre o ofício de professor", que tem me interpelado neste atual cotidiano tão insólito: 
Por isso, esse 'esperando não se sabe o quê' do título deve ser lido em relação a uma vontade infatigável de recomeçar, de novo e de novo, opondo ao curso natural das coisas essas separações cada vez mais esburacadas que constituem esta invenção bela, justa e boa que ainda chamamos de escola. Uma vontade, por outro lado, cada vez mais difícil de sustentar. Nessa lógica, não posso senão dedicar este livro a todos os professores e professoras de escolas (e universidades) públicas que, contra o vento e a maré, continuam fazendo bem o seu trabalho (continuam sendo professores) e levantando diques para que o mundo não se desfaça. Esses diques, é claro, nunca serão suficientemente sólidos, mas tentarão, pelo menos por um tempo, que o solo em que crescem as crianças e os jovens não seja completamente tóxico. (LARROSA, 2018, p. 11).

Convido todos/as a resistirmos e re-existirmos neste momento de pandemia.

\section{AGRADECIMENTOS}

Agradecimentos às professoras Aline Machado Dornelles e Maria do Carmo Galiazzi pela coordenação geral sensível e amorosa do CIRANDAR 2020; especialmente, agradeço a minha colega professora Diana Paula Salomão de Freitas, companheira em várias experiências acadêmico-profissionais, com a qual vivencio a inovação pedagógica na docência e na gestão co-partilhada.

\section{REFERÊNCIAS}

BRASIL. MINISTÉRIO DA EDUCAÇÃO. Resolução CNE/CP n ${ }^{\circ} 2$, de 20 de dezembro de 2019. Define as Diretrizes Curriculares Nacionais para a Formação Inicial de Professores para a Educação Básica e institui a Base Nacional Comum para a Formação Inicial de Professores da Educação Básica (BNC-Formação). Disponível em http://portal.mec.gov.br/docman/dezembro-2019-pdf/135951-rcp002-19/file Acesso em jan. 2020.

CARBOnELL, J. A aventura de inovar: a mudança na escola. Porto Alegre: Artmed Editora, 2002.

CUNHA, M. I. da. Inovações pedagógicas: tempos de silêncios e possibilidades de produção. Interface - Comunic., Saúde, Educ., v7, n13, p.149-58, ago 2003.

LARROSA, J. B. Esperando não se sabe o quê: sobre o ofício de professor. Autêntica Editora. Edição do Kindle, 2018. 
LARROSA, J. B. Notas sobre a experiência e o saber de experiência. Revista Brasileira de Educação. Jan/Fev/Mar/Abr, No 19, 2002.

LEITE, D.; GENRO, M. E. H.; BRAGA, A. M. e S. Inovações pedagógicas e demandas ao docente na universidade. In.: LEITE, D.; GENRO, M. E. H.; BRAGA, A. M. e S. (Orgs). Inovação e Pedagogia Universitária. Porto Alegre, Editora da UFRGS, 2011.

MELLO, E. M. B.; SALOMÃO DE FREITAS, D. P. Inovação Pedagógica - um princípio em movimento. Anais... IV Seminário de Inovação Pedagógica: vivências democráticas na relação ensino-aprendizagem. Unipampa, 04 e 05 dez. 2020. (No prelo).

Recebido em: 27 de maio de 2021.

Aceito em: 08 de junho de 2021. 